\title{
Ssciendo
}

DOI 10.2478/afepuc-2018-0010

(C) Acta Facultatis Educationis Physicae Universitatis Comenianae 2018, 58(2): 112-121

\section{VO $_{2}$ MAX LEVELS AS A POINTER OF PHYSIOLOGICAL TRAINING STATUS AMONG SOCCER PLAYERS}

\author{
Zerf Mohammed, Boras Fatima Zohar, Benali Gourar, Bengoua Ali, Mokkedes Moulay \\ Idriss
}

Physical Education Institute Laboratory OPAPS, University of Mostaganem, Mostaganem, Algeria

\begin{abstract}
Summary: The purpose of the current study was to evaluate the Aerobic endurance training as indicators of physiological training status among male soccer players. A total of 138 well-trained first division soccer players under 18 years were tested. Testing was based on the Cooper test as a one of simple tests to estimate $\mathrm{VO}_{2} \max$. $\mathrm{BMI}$ and $\mathrm{BFP}$ as valued anthropometric measurements to control body change relative to maximal oxygen consumption during dynamic exercise with large muscle groups benefit training time soccer training experience. Performance in this experience was based on the subjection that $60 \mathrm{ml} / \mathrm{kg} / \mathrm{min}$ of $\mathrm{VO}_{2} \mathrm{max}$ is the minimum fitness requirement for male soccer players to play at the elite level. Admit in this study as a protocol to categorise our sample into two groups (up and under the range $\mathrm{VO}_{2} \max \pm 60 \mathrm{ml} / \mathrm{kg} / \mathrm{min}$ ) and it was based on statistics applied and the design used. Our results highlighted the importance of aerobic performance up to $60 \mathrm{ml} / \mathrm{kg} / \mathrm{min}$ as the minimum fitness requirement to enhance the players' aerobic capacity allied to maximal heart rate relative to BFP levels as a better parameter in comparison with BMI for the prediction of low $\mathrm{VO}_{2} \mathrm{max}$ concomitant to the physiological training status as requests soccer performance demand.
\end{abstract}

Key words: $\mathrm{BFP}, \mathrm{BMI}, \mathrm{VO}_{2} \max$, physiological, soccer player 


\section{Introduction}

Enhanced aerobic endurance in soccer players needs for trainer to improved soccer performance by increasing the distance covered, enhancing work intensity, and increasing the number of sprints and involvements with the ball during a match (Hoff, Wisløff, Engen, Kemi \& Helgerud 2002). However, changes of anthropometry, body composition, and physical fitness during a soccer season in elite young athletes' variations throughout the different training periods (Fessi, Zarrouk, Filetti, Rebai, Elloumi \& Moalla 2016). Admit by soccer scientists studies at $60 \mathrm{ml} / \mathrm{kg} / \mathrm{min}$ of $\mathrm{VO}_{2}$ max suggested as the minimum fitness requirement for male soccer players to play at the elite level (Almeida, Santos Silva, Pedrinelli \& Hernandez 2018). Support by (Requena 2017) among Top-Level Professional Soccer Players evaluation of training programs must focus on regaining aerobic capacity and body composition. Investigate in the present founded on Obesity in terms of Fat percentage is a better parameter than BMI for the prediction of low $\mathrm{VO}_{2} \max$ (Mondal \& Mishra 2017). Backing by hypotheses; which confirm that Body fat percentage as a super factor affecting $\mathrm{VO}_{2}$ max and thus the cardiovascular status of the athletes (Anjali, Smita \& Deshmukh 2014).

Founded on the above and the pro recommendations: (a) that the average maximal oxygen intake for elite adult players is reported to be in the range of 55 to $69 \mathrm{ml} / \mathrm{kg} / \mathrm{min}$ (Coelho, Figueiredo, Elferink-Gemser \& Malina 2016). Where the $60 \mathrm{ml} / \mathrm{kg} / \mathrm{min}$ of $\mathrm{VO}_{2} \mathrm{max}$ is the minimum fitness requirement for male soccer players to play at the elite level (b) that Heart rate monitoring is a valid indicator of exercise intensity. Our analysis in the present study test $\mathrm{VO}_{2} \max$ levels as indices to estimate the adapted physiological soccer players' profile. Support by in this study based on $\mathrm{VO}_{2} \max \pm 60 \mathrm{ml} / \mathrm{kg} / \mathrm{min}$ as the protocol to test the effective Algerian training programs in the solicitation of maximal oxygen uptake allied to player training status correlates to its body adjustment relative to its actual performance.

\section{Methods}

A cross-sectional design was used to compare the stature, BMI, BFP and $\mathrm{VO}_{2}$ max. Players were classified based on their age categories under 18 years, sex male, senior teams from the Algerian championship national division one. Their age training exceeds 10 years. They play in the same championship, plus 2 years, category senior.

The data used in this study were obtained through the database of Team 5 Physical Education Institute Laboratory OPAPS for the academic year 2016 - 2017. In terms of playerrelated data, 148 male soccer players under 18 years, play at the Algerian championship 
national territory. Were examined in parameters (anthropometric and physiological decide for the current study) by Team 5 at the end of the physical preparation for the year $2016-2017$ after the agreement with their coach, were All examinations were realized for the first weeks before the start of the championship. Whereas too expert the study protocol and methods, we choose the laboratory OPAPS "Institute of Physical Education of our University" who approve it by the professors of football and physiologist of effort.

\section{TESTING PROTOCOL}

\section{The maximal aerobic capacity}

We have chosen the maximal aerobic capacity based on the formula Test Cooper [16] $\left(\mathrm{VO}_{2} \max =22.351 \mathrm{~d}(\mathrm{~km})-11.288 \mathrm{ml} / \mathrm{min} / \mathrm{kg}\right)$. Confirms by John Gormley et al. that the Cooper 12-minute test have a corresponding laboratory $\mathrm{VO}_{2} \max$ obtained by the formula (John \& Juliette 2009). Report by Daniel Mayorga-Vega, et al as an accurate test with validity around 90 - 95 \% (Mayorga-Vega, Bocanegra-Parrilla, Ornelas \& Viciana 2016). Support by the Cooper Institute as field test which provides a better picture of endurance of maximal aerobic capacity (Welk \& Meredith 2010) which leads to better health and a higher quality of life, according to (Sharon \& Hoeger 2015). However, Wener, Hoeger et al. confirm that $\mathrm{VO}_{2} \mathrm{max}$ is affected by genetics, training, gender, age, and body composition (W. Hoeger \& A.Hoeger 2016). While to calculate HRmax, we use the formula, proposed by Zerf (2017) derived from formula Uth N: Max Heart zones exercise $=\left(\mathrm{VO}_{2} \mathrm{max} / 15\right) *$ Heart Rate $(\mathrm{RHR})$. For RHR, we use the polar watch system to compute Heart Rate.

\section{Anthropometries fat index}

Height (m) and weight $(\mathrm{kg})$ were each measured in the standing position (Mohammed, Abelatif, Mokhtar \& Ali 2016) to calculate the body mass index BMI = weight $(\mathrm{kg}) / \mathrm{height}$ (m2) (Skidmore-Roth 2015 ). Goto et al. confirm that the $\mathrm{VO}_{2}$ peak is associated with biological status after controlling for height and weight (Goto, Yokokawa, Fukuda, Naito, Hisaoka et al. 2015). For body fat percentage (BFP), we use the formula proposed by Deurenberg, et al. body Fat $=(1,2 \times$ BMI $)+(0,23 \times$ age $)-(10,8 \times$ Sex $)-5,4$ (Deurenberg, Westrate \& Seidell 1991) s inexpensive and convenient means for our coaches and players.

\section{Statistical analyses}

Data analysis was performed using SPSS 22.0 for Windows (32- bit) (IBM, Armonk, NY, USA). Data obtained from the tests showed homogeneity and the deference according to the protocol used, presented as mean \pm standard deviation, Levene's test and independent $t$ - 
test, were the relationship between the variables was analysed by Pearson correlations ( $\mathrm{r}$ ). The statistical significance was set at $\mathrm{p}<0.05$

\section{Results}

Table 1

Present the characteristics and differences observed in the sampling

\begin{tabular}{|c|c|c|c|c|c|c|c|}
\hline & Groups & $\mathbf{N}$ & Mean \pm SD & $\mathbf{F}$ & $p<0.05$ & $\mathbf{T}$ & $p<0.05$ \\
\hline \multirow[t]{2}{*}{$\overline{\text { Weight (kg) }}$} & $\mathrm{VO}_{2} \max \geq 60 \mathrm{ml} / \mathrm{kg} / \mathrm{min}$ & 67 & $62,89 \pm 7,14$ & 5,493 & 0,021 & $-0,719$ & 0,474 \\
\hline & $\mathrm{VO}_{2} \max \leq 56 \mathrm{ml} / \mathrm{kg} / \mathrm{min}$ & 71 & $63,65 \pm 5,34$ & & & & \\
\hline \multirow[t]{2}{*}{ Height $(\mathrm{cm})$} & $\mathrm{VO}_{2} \mathrm{max} \geq 60 \mathrm{ml} / \mathrm{kg} / \mathrm{min}$ & 67 & $1,75 \pm 0,06$ & 2,305 & 0,131 & 1,247 & 0,214 \\
\hline & $\mathrm{VO}_{2} \max \leq 56 \mathrm{ml} / \mathrm{kg} / \mathrm{min}$ & 71 & $1,73 \pm 0,05$ & & & & \\
\hline \multirow[t]{2}{*}{$\overline{\mathrm{BMI}}(\mathrm{kg} / \mathrm{m} 2)$} & $\mathrm{VO}_{2} \max \geq 60 \mathrm{ml} / \mathrm{kg} / \mathrm{min}$ & 67 & $20,09 \pm 1,58$ & 1,173 & 0,281 & $-4,126$ & 0,000 \\
\hline & $\mathrm{VO}_{2} \max \leq 56 \mathrm{ml} / \mathrm{kg} / \mathrm{min}$ & 71 & $21,24 \pm 1,69$ & & & & \\
\hline \multirow[t]{2}{*}{$\mathrm{VO}_{2} \max$} & $\mathrm{VO}_{2} \max \geq 60 \mathrm{ml} / \mathrm{kg} / \mathrm{min}$ & 67 & $62,56 \pm 2,56$ & 5,984 & 0,016 & $-6,187$ & 0,000 \\
\hline & $\mathrm{VO} 2 \mathrm{max} \leq 56 \mathrm{ml} / \mathrm{kg} / \mathrm{min}$ & 71 & $56,93 \pm 2,02$ & & & & \\
\hline \multirow[t]{2}{*}{ BFP \% } & $\mathrm{VO}_{2} \max \geq 60 \mathrm{ml} / \mathrm{kg} / \mathrm{min}$ & 67 & $9,91 \pm 0,78$ & 5,836 & 0,017 & 14,364 & 0,000 \\
\hline & $\mathrm{VO}_{2} \max \leq 56 \mathrm{ml} / \mathrm{kg} / \mathrm{min}$ & 71 & $10,83 \pm 0,93$ & & & & \\
\hline \multirow[t]{2}{*}{$\overline{H R m a x} \%$} & $\mathrm{VO}_{2} \max \geq 60 \mathrm{ml} / \mathrm{kg} / \mathrm{min}$ & 67 & $187,75 \pm 7,64$ & 5,984 & 0,016 & $-6,187$ & 0,000 \\
\hline & $\mathrm{VO}_{2} \max \leq 56 \mathrm{ml} / \mathrm{kg} / \mathrm{min}$ & 71 & $170,62 \pm 5,96$ & & & & \\
\hline \multirow[t]{2}{*}{ AGE (years and month) } & $\mathrm{VO}_{2} \max \geq 60 \mathrm{ml} / \mathrm{kg} / \mathrm{min}$ & 67 & $17,50 \pm 0,59$ & 2,352 & 0,127 & 1,241 & 0,000 \\
\hline & $\mathrm{VO}_{2} \max \leq 56 \mathrm{ml} / \mathrm{kg} / \mathrm{min}$ & 71 & $17,38 \pm 0,50$ & & & & \\
\hline
\end{tabular}

Depending on data entry, the aims of the study and statistical processes applied within search limitation. Regarding the impact of Aerobic endurance training on physiological training status among our soccer. Our results in table 1 show that $\mathrm{VO}_{2}$ max of up to $\geq 60$ $\mathrm{ml} / \mathrm{kg} / \mathrm{min}$ is an advantage of physiological training response than its less. Claim in the present via the less fat or fatness among our soccer. Inspected via this study based on the sign of the independent T-test as deference record in BMI, BFP, HRmax and $\mathrm{VO}_{2}$ max. In the opposite of age, weight and height. Support by the correlate BFP as a superior index of obesity in term fat to predict the low $\mathrm{VO}_{2}$ max or HRmax more than BMI (table 2).

Table 2

Present Pearson Correlation between physiological and fat index among the total sample

\begin{tabular}{lllll}
\hline Pearson & $\mathrm{BMI}$ & $\mathrm{VO}_{2} \operatorname{maxX}$ & $\mathrm{BFP}$ & $\mathrm{HRmax}$ \\
\hline $\mathrm{VO}_{2} \mathrm{max}$ & $-0,43^{* *}$ & 1 & $-0,52^{* *}$ & $0,97^{* *}$ \\
\hline $\mathrm{HRmax}$ & $-0,45^{* *}$ & $0,97^{* *}$ & $-0,52^{* *}$ & 1 \\
\hline \multicolumn{5}{c}{$\mathrm{p}<0.05$} \\
& $\mathrm{~N}$ & & \\
\cline { 2 - 5 } & 138 & & \\
\hline
\end{tabular}


Interpret by (James, Robin, Claire, Andrea \& Rodney 2016) via the decline in cardiovascular fitness, owing to the increase of fat overweight or obesity levels. Suggesting this control and training method as a targeted approach used to determine training errors allied to the efforts to achieve optimal improvement in physical fitness performance. The case of this study, supported by previous prevalence studies through the importance of players and coaches to access soccer player's physical status for team selection and training purposes. Admit by Physiological tests as control tools providing information relative to the difficulties in performing the intense physical exertion (Gonçalves \& Silva 2016). Establish in this study via $\mathrm{VO}_{2}$ max upper to $60 \mathrm{ml} / \mathrm{kg} / \mathrm{min}$ as exercise intensity consistent with exercise maximum and energy requirements Zerf 2017. Backing by (Cardoso, Baumgart, Jansen, Freiwald \& Hoppe 2018) among individual player data were more variance is recorded through $\mathrm{VO}_{2} \mathrm{max}$ total endurance and physical abilities due to the amount of anaerobic or aerobic energy supply. Needing from our trainers a combination of various tests to provide a comprehensive assessment of the players that permitting the optimization of training and testing procedures for soccer players. The case of this study, which confirm the levels of Aerobic endurance training up $60 \mathrm{ml} / \mathrm{kg} / \mathrm{min}$ to as super indicators of physiological training status recommended for our soccer players to reach the high and global levels derived from soccer sciences research.

\section{Discussion}

Based on the study design and statistical applied. Our results confirm:

1. $\mathrm{VO}_{2} \max$ up to $\geq 60 \mathrm{ml} / \mathrm{kg} / \mathrm{min}$ is effective endurance training to improve maximal oxygen uptake, admit in this study as advanced physiological training response than it's under among soccer players. State by (Scribbans, Vecsey, Hankinson, Foster \& Gurd 2016) that training at any intensity above $\sim 60 \%$ of $\mathrm{VO}_{2} \max$ is likely to improve maximal oxygen uptake in healthy adults. As well as the decreases body weight or stroke. Confirmed by Hassane, LeMoal, Wong, Ounis, Castagna, Duluc, Owen \& Drust 2013) in the context of training-related to increased $\mathrm{VO}_{2} \mathrm{max}$ after training at high intensity. Indicate by (Thevenet, Tardieu, Zouhal et al. 2007) through the amount of oxygen consumed during exercise that could serve as a good criterion to judge the effectiveness of this exercise on the development of physiological soccer game recruitment. State in the present study through the inverse correlation between $\mathrm{VO}_{2}$ max and the fat index used in this study. Where their upper reduce the levels of aerobic fitness capacity. Shown in 
similar, as the basis for a good form of sports players' formation. Support by a number of tests through the increase of the level of maximum oxygen uptake $\left(\mathrm{VO}_{2} \mathrm{max}\right)$, improves the sports performance of the game. Reviewed by Fortuna, Szczurowski, Zabłocki, Pałasz \& Demczyszak (2018) above the player lengthens the distance run during the match, the intensity of the globally performed work increases, the number of sprints increases and the number of actions with the ball increases.

2. $\mathrm{VO}_{2} \max$ up to $\geq 60 \mathrm{ml} / \mathrm{kg} / \mathrm{min}$ for a soccer player is effective endurance training to control body fat or fatness (BFP or BMI). Our results table 1 and 2 lines with Koutlianos, Dimitros, Metaxas, Cansiz, Deligiannis \& Kouidi (2013) which confirm the impact of body fat composition in term overweight on physiological capacity. Support by (Mondal \& Mishra 2017) via the prediction of the low $\mathrm{VO}_{2} \max$. Confirmed by Laxmi CC (Laxmi, Udaya \& Shankar 2014) trendy the effects of increasing fat in compared with muscle mass on Cardiorespiratory Fitness case sports studies and distribution adiposity case the medical studies, according to Tauseef Nab et al. (2015). Although based on the strong negative correlation between $\mathrm{VO}_{2} \mathrm{max}, \mathrm{BFP}$ and $\mathrm{BMI}$, we agree that an increase in $\mathrm{BM}$ of $1 \mathrm{~kg}$ can increase the aerobic demand of exercise by 1 to $14 \%$. Disclose in similar as a significant negative correlation between $\mathrm{BMI}$ and $\mathrm{VO}_{2} \max (\mathrm{ml} / \mathrm{kg} / \mathrm{min})$ signifying the possibility of body fat effect on cardiorespiratory function (Radovanović, Kocić, Gajović, Radević, Milosavljević \& Nićiforović 2014). From the above, we subject for our trainers, $\mathrm{VO}_{2} \mathrm{max}$ up to $\geq 60 \mathrm{ml} / \mathrm{kg} / \mathrm{min}$ as an effective endurance training to improve the soccer player's maximal oxygen uptake relative to their body weight adjustment allied to fat accumulation. Record in this study through adaptive concerns bodily functions associated with oxygen consumption. Set by similar as an advantage in the benefits of the top team compared with those in the lowest place among the Norwegian elite league, according to Hoff, Wisløff, Engen, Kemi \& Helgerud (2002). Interpret by Hassane, LeMoal, Wong, Ounis, Castagna, Duluc, Owen \& Drust (2013) as a training body adaptation, allied to body composition management (Paul, Don, Kimberley et al. 2016). Admit in this study via the levels of aerobic capacity relative to changes in body fat percent (Mohammed, Abelatif, Mokhtar \& Ali 2016) as efficient endurance training to improve maximal oxygen uptake allied to physiological soccer demand. Conclude via this study, based on V02max upper to $60 \mathrm{ml} / \mathrm{kg} / \mathrm{min}$ as benefit physiological training status to control the appropriate percentage body fat as the most important body weight management (Draper \& Marshall 2014) more associated with the prediction of lesser $\mathrm{VO}_{2} \max$. 
Recommended through this study as the most typical method for our trainers to monitor body weight or stroke relative to aerobic fitness levels recommended in this game. Recommend through the high $\mathrm{VO}_{2} \max$ as adopt soccer training (McMillan, Helgerud, Macdonald \& Hoff 2005). Requesting for our coaches the use of our protocol to have access to objective information on soccer player's physical status for team selection and training purposes. Appraisal in this study via Physiological tests that can provide the soccer adaptation profile supported by the analysis of body composition allied to $\mathrm{VO}_{2}$ max levels (Zerf 2018). State in the current study through $\mathrm{VO}_{2}$ max super to $\geq 60 \mathrm{ml} / \mathrm{kg} / \mathrm{min}$ as the minimum fitness requirement to enhance the Algerians player maximal heart rate relative to BFP levels as a better parameter than BMI for the prediction of low $\mathrm{VO}_{2}$ max concomitant to the physiological soccer status performance demands.

\section{Conclusion}

Our results approve that a training response in soccer game requests $\mathrm{VO}_{2}$ max upper to $\geq 60 \mathrm{ml} / \mathrm{kg} / \mathrm{min}$ as the minimum fitness requirement to enhance the player maximal heart rate relative to BFP levels as a better parameter than BMI for the prediction of the lower $\mathrm{VO}_{2}$ max. Subjected via this study as accurate systems to monitor the physiological adaptations of soccer training program simultaneously to their endurance training to improve maximal oxygen uptake. Recorded via this study as individual training mistakes to enhance the Algerians players' aerobic endurance performance. Inspected by similar as key soccer status demand to perform at the elite level. Recommended trendy this study via individuation of players load, which should be measured in appropriation with $\mathrm{VO}_{2}$ max related to \% $\mathrm{BF}$ level. Considered in similar as a factor that contributes to enhancing the individually based training programs. Admit by soccer scientists studies at $60 \mathrm{ml} / \mathrm{kg} / \mathrm{min}$ of $\mathrm{VO}_{2} \mathrm{max}$ recommended as the smallest fitness requirement among European male soccer players to play in the elite level.

\section{References}

1. AlMEIDA, A.M.D., P.R. SANTOS SILVA, A. PEDRINELli \& A. J. HERNANDEZ, 2018. Aerobic fitness in professional soccer players after anterior cruciate ligament reconstruction. $\quad P L O S \quad O N E, \quad$ e0194432. doi:https://doi.org/10.1371/journal.pone.0194432.

2. ANJALI, N. SHETE, SMITA S BUTE \& P.R. DESHMUKH, 2014. A Study of $\mathrm{VO}_{2}$ max and Body Fat Percentage in Female Athletes. J Clin Diagn Res. 8(12), BC01-BC03. doi:10.7860/JCDR/2014/10896.5329. 
3. CARDoso DE ARAÚJO, M., C. BAUMGART, C. T. JANSEN, J. FREIWALD \& M. W. HOPPE, 2018. Sex Differences in Physical Capacities of German Bundesliga Soccer Players. J Strength Cond Res, https://www.ncbi.nlm.nih.gov/pubmed/29927885. doi:10.1519/JSC.0000000000002662.

4. MAYORGA-VEGA, D., R. BOCANEGRA-PARRILLA, M. ORNELAS \& J. VICIANA, 2016. Criterion-Related Validity of the Distance- and Time-Based Walk/Run Field Tests for Estimating Cardiorespiratory Fitness: A Systematic Review and Meta-Analysis. PLoS One. 11(3), e0151671. doi:10.1371/journal.pone.0151671.

5. DEURENBERG, P., J. A. WESTRATE \& J. C. SEIDELL, 1991. Body mass index as a measure of body fatness: age- and sex-specific prediction formulas. Br J Nutr. 65, $105-$ 114.

6. DRAPER, N. \& H. MARSHALL, 2014. Exercise Physiology: For Health and Sports Performance. USA: Routledge.

7. DE ANDRADE GONÇALVES, A. C. \& D. A. SANTOS SILVA, 2016. Factors associated with low levels of aerobic fitness among adolescents. Revista Paulista de Pediatria, 2. doi:http://dx.doi.org/10.1016/j.rppede.2015.06.025

8. FESSI, M. S., N. ZARROUK, C. FILETTI, H. REBAI, M. ELLOUMI \& W. MOALLA, 2016. Physical and anthropometric changes during pre- and in-season in professional soccer players. J Sports Med Phys Fitness. 56(10), 1163-1170. doi:PMID: 26364664

9. FORTUNA, M., J. SZCZUROWSKI, T. ZABŁOCKI, D. PAŁASZ \& I. DEMCZYSZAK, 2018. Estimation of evaluation some spirometric's parameters of football players during preparation period. Journal of Education, Health and Sport. 8(6), 69-79. doi:http://dx.doi.org/10.5281/zenodo.1252282.

10. GOTO, Y., H. YOKOKAWA, H. FUKUDA, T. NAITO, T. HISAOKA et al., 2015. Body mass index and waist circumference are independent risk factors for low vital capacity among Japanese participants of a health checkup: a single-institution cross-sectional study. Environ Health Prev Med, Body mass index and waist circumference are independent risk factors for low vital capacity among Japanese participants 20, 108-115.

11. HASSANE, Z., G. E. LEMOAL, P. WONG, G. O. BENOUNIS, G. C. CASTAGNA, G. C. DULUC, G. A. L. OWEN \& B. DRUST, 2013. Physiological Responses of General vs. Specific Aerobic Endurance Exercises in Soccer. Asian J Sports Med. Sep; 4(3), 213-220. Retrieved from https://www.ncbi.nlm.nih.gov/pmc/articles/PMC3880666/ 
12. HOFF, J., U. WISLØFF, L. C. ENGEN, O. J. KEMI \& J. HELGERUD, 2002. Soccer specific aerobic endurance training. British Journal of Sports Medicine (BJSM). 36(3), 218-221. doi:http://dx.doi.org/10.1136/bjsm.36.3.218

13. JAMES, J. D., M. O. ROBIN, L. S. ClAIRE, A. V. ANDREA \& P. RODNEY, 2016. Associations between anthropometric characteristics and physical performance in male law enforcement officers: a retrospective cohort study. Ann Occup Environ Med. 28(26), 1-7. doi:10.1186/s40557-016-0112-5

14. JOHN, G. \& H. JULIETTE, 2009. Exercise Therapy: Prevention and Treatment of Disease. US: Wiley.com.

15. McMillan, J., R. HELGERUD, R. MACDONALD \& J. HOFF, 2005. Physiological adaptations to soccer-specific endurance training in professional youth soccer players. British Journal of Sports Medicine. 39(5), 273-277. doi:http://dx.doi.org/10.1136/bjsm.2004.012526.

16. LAXMI, C. C., I. B. UDAYA \& S. VINUTHA SHANKAR, 2014. Effect of body mass index on cardiorespiratory fitness in young healthy males. International Journal of Scientific and Research Publications. 4(2), 1-4. Retrieved from www.ijsrp.org.

17. SKIDMORE-ROTH, L., 2015. Mosby's Drug Guide for Nursing Students, with 2016 Update. US: Elsevier Health Sciences.

18. ZERF, M., 2018. Aerobic Fitness as a Superior Predictor Factor to Estimate the Optional Body Weight among the Soccer Players. 2:. J. Hum Bio \& Health Edu, 2, 010. Retrieved from $\quad$ https://bioaccent.org/humanbiology-healtheducation/humanbiologyhealtheducation10.php.

19. COELHO E SILVA, M., J., J. A. FIGUEIREDO, M. T. ELFERINK-GEMSER, \& R. M. MALINA, 2016. Assessment of biological maturation in adolescent athletes: application of different methods with soccer and hockey players. Portuguese: University the Colomba.

20. MOHAMMED, Z., H. ABELATIF, M. MOKHTAR \& B. ALI, 2016. Height versus Weight which Cassel Parameter Determine Pulmonary Functions Fitness among the Algerians Soccer Players. J Pulm Respir Med. 6(353). doi:10.4172/2161-105X.1000353.

21. MONDAL, H. \& S. P. MISHRA, 2017. Effect of BMI, Body Fat Percentage and Fat Free Mass on Maximal Oxygen Consumption in Healthy Young Adults. J Clin Diagn Res. 11(6), CC17-CC20. doi:10.7860/JCDR/2017/25465.10039.

22. KOUTLIANOS, N., E. DIMITROS, T. METAXAS, M. CANSIZ, A. S. DELIGIANNIS \& E. KOUIDI, 2013. Indirect estimation of $\mathrm{VO}_{2} \max$ in athletes by ACSM's equation: valid or not? Hippokratia. 17(2), 136-140. 
23. PAUL, I, R. DON, M. KIMBERLEY et al., 2016. Nutrition. US: Jones and Bartlett Publishers.

24. RADOVANOVIĆ, S., S. KOCIĆ, G. GAJOVIĆ, S. RADEVIĆ, M. MILOSAVLJEVIĆ \& J. NIĆIFOROVIĆ, 2014. The impact of body weight on aerobic capacity. Med Glas (Zenica). 11(1), 204-9. Retrieved from https://www.ncbi.nlm.nih.gov/pubmed/24496365.

25. REQUENA B, 2017. Off-Season Effects on Functional Performance, Body Composition, and Blood Parameters in Top-Level Professional Soccer Players. J Strength Cond Res. 31(4), 939-946. doi:10.1519/JSC.0000000000001568.

26. HOEGER, S. A., 2015. Principles and Labs for Fitness and Wellness. US: Cengage Learning, Inc.

27. TAUSEEF, N, R. NADEEMA \& Q. OUBER, 2015. Assessment of cardiovascular fitness $\left[\mathrm{VO}_{2} \mathrm{max}\right]$ among medical students by Queens College step test. International Journal of Biomedical and Advance Research. 6(5), 418-421. doi: 10.7439/ijbar.

28. WELK, G. \& M. D. MEREDITH, 2010. Fitnessgram and Activitygram Test Administration Manual-Updated 4th Edition. US: Human Kinetics.

29. THEVENET, D., M. TARDIEU, H. ZOUHAL et al., 2007. Influence of exercise intensity on time spent at high percentage of maximal oxygen uptake during an intermittent session in young endurance-trained athletes. Eur $J$ Appl Physiol. 102(1), 19-26. doi:https://doi.org/10.1007/s00421-007-0540-6

30. SCRIBBANS, T. D., S. VECSEY, P. B. HANKINSON, W. S. FOSTER \& B. J. GURD, 2016. The Effect of Training Intensity on $\mathrm{VO}_{2}$ max in Young Healthy Adults: A MetaRegression and Meta-Analysis. Int J Exerc Sci, 9(2), 230-247. Retrieved from https://www.ncbi.nlm.nih.gov/pmc/articles/PMC4836566/.

31. HOEGER, W.K. \& S. A. HOEGER, 2016. Lifetime Physical Fitness and Wellness: A Personalized Program. US: CengageBrain.com.

32. ZERF, M., 2017. Influence of maximum heart rate predicts method on appropriate exercise intensity via Algerian soccer training programs. Turkish Journal of Sport and Exercise, 254 - 260. doi:http://dx.doi.org/10.15314/tsed.323317. 